Wiraraja Medika : Jurnal Kesehatan
https://www.ejournalwiraraja.com/index.php/FIK
2088-415x (Print)|2685-9998 (online)

\title{
Dampak Penggunaan Gadget Dengan Tingkat Kematangan Sosial Anak Prasekolah
}

\author{
Anju Picesya Nababan ${ }^{1}$, Tuti Asrianti Utami ${ }^{2}$, Wilhelmus Hary Susilo ${ }^{3}$ \\ ${ }^{1,2,3}$ Program Sarjana Keperawatan, STIK Sint Carolus \\ tutichaidir18@gmail.com* \\ *Corresponding author
}

\begin{tabular}{ll}
\hline Informasi artikel & ABSTRAK \\
\hline Sejarah artikel: & Anak prasekolah yang sedang berada ditahap gemar mengeksplor hal-hal \\
Received: 05-04-2021 & baru banyak ditemukan menggunakan gadget untuk bermain sehingga jarang \\
Revised: 25-05-2021 & berinteraksi dengan lingkungannya. Penelitian dilakukan untuk mengetahui \\
Accepted: 30-05-2021 & faktor-faktor dampak penggunaan gadget dengan tingkat kematangan sosial \\
\hline Kata kunci: & anak prasekolah di Kelurahan Cigadung Pandeglang. Penelitian ini \\
Prasekolah, kematangan & menggunakan desain cross sectional dengan menggunakan kuesioner. Sampel \\
sosial, gadget, ibu & penelitian adalah ibu dengan anak prasekolah sebanyak 195 responden. Uji \\
& statistik menggunakan uji Kendall's tau-c. Hasil penelitian menyatakan \\
& kurangnya tingkat kematangan sosial anak prasekolah sebanyak 56.9\%. \\
& Faktor Karakteristik ibu juga diteliti dan hasilnya menyatakan tidak adanya \\
& hubungan usia ibu $(p=0,094)$, pendidikan ibu ( $p=-0,074)$, pekerjaan $(p=-$ \\
& 0,53), paritas ( $p=-0,38)$, pengetahuan $(p=-0,068)$ dan ada hubungan \\
& signifikan antara lama bermain gadget ( $p=0,042)$ dengan tingkat \\
& kematangan sosial anak prasekolah. Peneliti berharap ibu dapat lebih \\
& memperhatikan dan memantau setiap perkembangan dan kematangan sosial \\
anak sejak dini.
\end{tabular}

Key word: preschool, social maturity, gadget, mothers

\begin{abstract}
Preschoolers who are in the stage are fond of exploring new things, many are found using gadgets to play so they rarely interact with their environment. The study was conducted to determine the impact factors of the use of gadgets with the level of social maturity of preschoolers in Cigadung Pandeglang Village. This study uses a cross sectopnal design using a questionnaire. The sample of the study was 195 mothers with preschool children. Statistical tests using the Kendall's tau-c test. The results of the study stated the lack of social maturity level of preschool children was 56.9\%. Maternal Characteristics Factors were also examined and the results revealed no relationship between maternal age $(p=0.094)$, maternal education ( $p=-0.074)$, occupation $(p=-0.53)$, parity $(p=-0.38)$, knowledge $(p=-0.068)$ and there is a significant relationship between the length of playing gadget $(p=0.042$ ) with the level of social maturity of preschool children. Researchers hope that mothers can pay more attention \& monitor every child's development and social maturity from an early age.
\end{abstract}

\section{PENDAHULUAN}

Gadget adalah alat yang berisi media informasi, permainan ataupun hiburan yang dapat mempengaruhi sikap, pola pikir ataupun perilaku seseorang (Hudaya, 2018). Gadget diciptakan dengan berbagai aplikasi yang dapat menyajikan berbagai media berita, jejaring sosial, hobi, bahkan hiburan (Jati, H, 2014). Di dunia sebanyak 72\% anak yang berusia dibawah delapan tahun sudah mulai menggunakan gadget seperti smartphone, tablet, ipod sejak tahun 2013. Angka tersebut meningkat dua kali lipat dibandingkan 2011 yang berada di angka 38 persen (Fajrianna, 2015) dan di Indonesia sendiri 9\% anak usia 3 sampai 6 tahun sudah menggunakan gadget (Widiawati,S.E, 2014).

Masa prasekolah adalah fase anak sedang ada ditahap gemar mengeksplor halhal baru disekitarnya, mengetahui hal-hal yang sebelumnya belum pernah dia jumpai 
atau alami. Anak prasekolah (3-6 tahun) memiliki rasa ingin tahu dan daya imajinasi yang tinggi. Hardjawikarta, C. G (2018) mengatakan anak-anak usia dibawah 5 tahun sebaiknya lebih banyak menggunakan sensor-motoriknya seperti bergerak, berlari, meraih sesuatu, berinteraksi dengan lingkungan sekitarnya.

Banyak ditemukan orangtua yang menggunakan gadget sebagai penenang anaknya agar tidak mengganggu pekerjaan yang memberikan dampak negatif karena anak akan mengalami rasa candu, cenderung menjadi individualis dan anak akan sulit berkembang (Al-Ayouby.M, 2017). Chusna P. A (2017) mengatakan gadget menurunkan kemampuan anak untuk berinteraksi dengan lingkungan sosialnya. ibu berperan dalam perkembangan anak, maka ibu seharusnya mengetahui informasi yang cukup terutama mengenai keefektifan waktu anak dalam menggunakan gadget (Setianingsih S, 2018)

Berdasarkan pengamatan yang dilakukan di Kelurahan Cigadung Pandeglang didapatkan bahwa masih banyak ibu yang memberikan gadget kepada anaknya agar anaknya tenang dan tidak menangis saat ibunya sedang melakukan pekerjaan rumah. Banyak ditemukan walaupun anak bermain bersama temannya, namun tidak ada interaksi yang terjadi, karena terfokus pada gadget-nya masing-masing. Penelitian ini bertujuan untuk mengetahui dampak penggunaan gadget pada anak usia prasekolah.

\section{METODE PENELITIAN}

Penelitian ini menggunakan metode kuantitatif, desain observasional deskriptif korelasi dengan pendekatan cross sectional. Populasinya semua ibu yang memiliki anak usia prasekolah di kelurahan Cigadung Pandeglang sebanyak 747 ibu. Sampel penelitian menggunakan table krejtcie sebanyak 195 ibu dengan purposive sampling berdasar kriteria inklusi yaitu ibu dengan anak usia prasekolah, menggunakan gadget selama 1 tahun lebih dan tinggal di kelurahan Cigadung Pandeglang. Kuisioner sebanyak 14 pernyataan telah di uji validitas \& reliabilitas didapatkan Alpha Cronbach's $(0,700)$ dan instrument kuesioner VSMS (Vineland Social Maturity Scale) untuk mengukur tingkat kematangan sosial anak oleh Edgar A Doll. Kuesioner ini merupakan kuesioner baku Alpha Cronbach's $(\alpha)=0.92(\mathrm{r} \geq 0.700)$ dan koefisien korelasi $\mathrm{r}$ tabel $=0.85(\alpha>\mathrm{r}$ tabel $)$ (Sari 2016). Uji validitas dan reabilitasnya didapatkan hasil yang didapatkan koefisien $r=0.85$. Penelitian ini dilakukan di Kelurahan X pada bulan Mei sampai Juni 2020. Analisa data univariat menggunakan distribusi frekuensi dan uji bivariat menggunakan uji Kendall's tau-c. Penelitian ini melalui uji Komisi Etik Penelitian \& Pengembangan Kesehatan STIK Sint Carolus No: 028/KEPPKSTIKSC/III/2020.

\section{HASIL PENELITIAN}

Tabel 1. Distribusi Frekuensi Karakteristik Ibu di Kelurahan Cigadung Pandeglang, lama bermain dan kematangan sosial anak

\begin{tabular}{lcc}
\hline Karakteristik & f & \% \\
\hline Usia & & \\
Usia $<31$ tahun & 77 & $39,5 \%$ \\
Usia $\geq 31$ tahun & 118 & $60,5 \%$ \\
\hline Pendidikan & & \\
SD-SMP & 19 & $9,7 \%$ \\
SMA-Sarjana & 176 & $90,3 \%$ \\
\hline Pekerjaan & & \\
Tidak Bekerja & 89 & $45,6 \%$ \\
Bekerja & 106 & $54,4 \%$ \\
\hline Paritas & & \\
Primipara & 61 & $31,3 \%$ \\
Multipara & 122 & $62,6 \%$ \\
Grandemultipara & 12 & $6,2 \%$ \\
\hline Pengetahuan & & \\
Cukup & 21 & $10,8 \%$ \\
Baik & 174 & $89,2 \%$ \\
\hline Lama Bermain & & \\
Tinggi>3 kali & 31 & $15.9 \%$ \\
Sedang 2-3 kali & 81 & $41.9 \%$ \\
Rendah 1-2 kali & 83 & $42.6 \%$ \\
\hline Kematangan & & \\
Sosial Anak & & \\
Kurang & 111 & $56.9 \%$ \\
Lebih & 29 & $14.9 \%$ \\
Sesuai & 55 & $28.2 \%$ \\
\hline
\end{tabular}

Tabel 1 diatas menjelaskan bahwa sebagian besar responden adalah ibu dengan usia $\geq 31$ tahun sebanyak 118 (60,5\%), pendidikan terakhir SMA sampai Perguruan Tinggi sebanyak 176 (90,3\%), tidak bekerja sebanyak 89\%, multipara sebanyak 122 (62,6\%), pengetahuan cukup sebanyak $174(89,2 \%)$, lama bermain gadget dengan kategori kurang sebanyak 83 (42.6\%). kematangan sosial anak terbanyak dengan kategori rendah sebanyak 111 $(56,9 \%)$. 
Tabel 2. Hubungan antara usia, pendidikan, pekerjaan, paritas, pengetahuan ibu dan lama bermain gadget dengan Kematangan Sosial Anak Prasekolah di Kelurahan Cigadung Pandeglang

\begin{tabular}{|c|c|c|c|c|c|c|c|c|c|c|}
\hline \multirow{3}{*}{\multicolumn{2}{|c|}{ Karakteristik }} & \multicolumn{6}{|c|}{ Kategori Kematangan Sosial } & \multirow{2}{*}{\multicolumn{2}{|c|}{ Total }} & \multirow{3}{*}{$\begin{array}{c}P \\
\text { value }\end{array}$} \\
\hline & & \multicolumn{2}{|c|}{ Kurang } & \multicolumn{2}{|c|}{ Lebih } & \multicolumn{2}{|c|}{ Sesuai } & & & \\
\hline & & $\mathrm{n}$ & $\%$ & $\mathrm{n}$ & $\%$ & $\mathrm{~N}$ & $\%$ & $\mathrm{~N}$ & $\%$ & \\
\hline \multirow[t]{2}{*}{ Usia } & $<31$ tahun & 48 & $62,3 \%$ & 11 & $14,3 \%$ & 18 & $23,4 \%$ & 77 & $100 \%$ & \\
\hline & $\geq 31$ tahun & 63 & $53,4 \%$ & 18 & $15,3 \%$ & 37 & $31,4 \%$ & 118 & $100 \%$ & 0,094 \\
\hline \multirow[t]{2}{*}{ Pendidikan } & $\begin{array}{l}\text { (SD \& } \\
\text { SMP) }\end{array}$ & 8 & $42,1 \%$ & 2 & $10,5 \%$ & 9 & $47,4 \%$ & 19 & $100 \%$ & \\
\hline & $\begin{array}{l}\text { (SMA \& } \\
\text { PT) }\end{array}$ & 103 & $58,5 \%$ & 27 & $15,3 \%$ & 46 & $26,1 \%$ & 176 & $100 \%$ & $-0,074$ \\
\hline \multirow[t]{2}{*}{ Pekerjaan } & Bekerja & 64 & $60,4 \%$ & 12 & $11,3 \%$ & 30 & $28,3 \%$ & 106 & $100 \%$ & \\
\hline & $\begin{array}{l}\text { Tidak } \\
\text { Bekerja }\end{array}$ & 47 & $52,8 \%$ & 17 & $19,1 \%$ & 25 & $28,1 \%$ & 89 & $100 \%$ & $-0,53$ \\
\hline \multirow[t]{3}{*}{ Paritas } & Primipara & 33 & $54,1 \%$ & 10 & $16,4 \%$ & 18 & $29,5 \%$ & 61 & $100 \%$ & \multirow{3}{*}{$-0,38$} \\
\hline & \multirow{2}{*}{$\begin{array}{l}\text { Multipara } \\
\text { Grande- } \\
\text { multipara }\end{array}$} & 70 & $57,4 \%$ & 17 & $13,9 \%$ & 35 & $28,7 \%$ & 122 & $100 \%$ & \\
\hline & & 8 & $66,7 \%$ & 2 & $16,7 \%$ & 2 & $16,7 \%$ & 12 & $100 \%$ & \\
\hline \multirow[t]{2}{*}{ Pengetahuan } & Cukup & 8 & $38,1 \%$ & 6 & $28,6 \%$ & 7 & $33,3 \%$ & 21 & $100 \%$ & \multirow[b]{2}{*}{$-0,068$} \\
\hline & Baik & 103 & $59,2 \%$ & 23 & $13,2 \%$ & 48 & $27,6 \%$ & 14 & $100 \%$ & \\
\hline \multirow{3}{*}{$\begin{array}{l}\text { Lama } \\
\text { gadget }\end{array}$} & Tinggi & 18 & $58.1 \%$ & 6 & $19.4 \%$ & 7 & $22.6 \%$ & 31 & $100 \%$ & \multirow{3}{*}{0,042} \\
\hline & Sedang & 49 & $60.5 \%$ & 8 & $9.9 \%$ & 24 & $29.6 \%$ & 81 & $100 \%$ & \\
\hline & Rendah & 44 & $53.0 \%$ & 15 & $18.1 \%$ & 24 & $28.9 \%$ & 83 & $100 \%$ & \\
\hline
\end{tabular}

Tabel 2 menjelaskan bahwa ibu yang berusia $\geq 31$ tahun memiliki anak usia prasekolah mayoritas dengan tingkat kematangan sosial kurang sebanyak 63 (53.4\%) responden di kelurahan Cigadung Pandeglang. Hasil uji Kendall's tau-c didapatkan $p$ value $0,094 \quad(p>\quad 0,05)$ disimpulkan tidak terdapat hubungan usia ibu dengan tingkat kematangan sosial anak prasekolah. Ibu berpendidikan tinggi (SMA - Perguruan Tinggi) yang memiliki anak usia prasekolah mayoritas memiliki tingkat kematangan sosial kurang sebanyak 103 (58.5\%) responden di kelurahan X. Hasil uji Kendall's tau-c didapatkan nilai $p$ value0,074 yang berarti tidak adanya hubungan signifikan pendidikan dengan tingkat kematangan sosial anak prasekolah.

Ibu bekerja memiliki anak usia prasekolah mayoritas dengan tingkat kematangan sosial kurang sebanyak 64 $(60,4 \%)$ responden di kelurahan X. Hasil uji Kendall's tau-c $p=-0,053$ yang berarti didapatkan tidak adanya hubungan signifikan pekerjaan dengan kematangan sosial anak prasekolah. Ibu multipara yang memiliki anak usia prasekolah dengan tingkat kematangan sosial kurang sebanyak $70 \quad(57,4 \%)$ responden di kelurahan Cigadung Pandeglang. Hasil uji Kendall's tau-c didapatkan hasil $p$ value -0,038 yang berarti tidak ada hubungan paritas dengan tingkat kematangan sosial anak prasekolah.

Ibu dengan pengetahuan baik yang memiliki anak usia prasekolah mayoritas dengan tingkat kematangan sosial kurang sebanyak 103 (59.2\%) didapatkan nilai $p=$ 0,068 yang berarti tidak adanya hubungan signifikan pengetahuan dengan tingkat kematangan sosial anak prasekolah. Lama bermain gadget rendah pada anak usia prasekolah di Kelurahan X yang memiliki tingkat kematangan sosial kurang adalah sebanyak $44 \quad(53,0 \%)$ didapatkan nilai $p=0,042 \quad(p<0,05)$ yang berarti adanya hubungan signifikan lama bermain gadget dengan tingkat kematangan sosial anak prasekolah. 


\section{PEMBAHASAN}

Usia berpengaruh pada keaktifan seseorang untuk berpartisipasi, ibu dengan usia lebih tua dianggap lebih berpengalaman dan banyak memberikan pendapat dalam hal menetapkan keputusan (Sari, EM., 2015). Penelitian ini menjelaskan tidak adanya hubungan usia ibu dengan tingkat kematangan sosial anak prasekolah dikarenakan usia ibu belum tentu menandakan bahwa ibu sudah siap atau matang secara mental untuk mampu mengerti maupun membantu anaknya dalam proses pencapaian tingkat kematangan sosial yang baik (Meiri E, dkk 2020). Ditemukan beberapa ibu di Kelurahan Cigadung Pandeglang walaupun saat ini memiliki usia yang matang namun saat mereka menghadapi pernikahan, mereka masih berada diusia yang terbilang sangat muda. Ketika seorang anak tumbuh dan menghadapi perubahan-perubahan dalam situasi kehidupannya, dia membutuhkan banyak dukungan dan akan bergantung pada ibunya maka hal ini membuat ibu sangat membutuhkan kematangan emosi dan mental yang baik (T.M, 2019).

Pendidikan membuat adanya perubahan sikap dan tata laku seseorang atau kelompok yang mendewasakan manusia melalui upaya pengajaran dan pelatihan. Seseorang yang memiliki pendidikan tinggi akan cenderung banyak mendapatkan informasi dan pengetahuan (Notoatmodjo, 2014). Penelitian Rini, 2016 menjelaskan bahwa tidak ada hubungan yang signifikan antara pendidikan ibu dengan perkembangan anak karena perkembangan anak tidak hanya berhubungan dengan pendidikan ibu saja tetapi juga dipengaruhi faktor lain seperti faktor fisik (seperti sanitasi, keadaan rumah, radiasi). Faktor fisik merupakan lingkungan yang sangat menentukan akan tercapai atau tidaknya potensi bawaan (genetik), lingkungan yang baik akan mempengaruhi individu setiap harinya begitupula sebaliknya (Arifin. S, 2015). Berbeda dengan penelitian Fitria, 2016 menjelaskan ada hubungan pendidikan orangtua dengan perkembangan sosial anak $(p=0,004)$. Penelitian ini menjelaskan tidak adanya hubungan pendidikan dengan tingkat kematangan sosial anak prasekolah dikarenakan masih banyaknya kepercayaan di Kelurahan X bahwa masyarakat mengejar pendidikan karena hanya membutuhkan agar mendapatkan pekerjaan yang baik tanpa memikirkan jenis pendidikan apa yang ditempuh hal ini dibuktikan dengan banyak ditemukan masyarakat yang menempuh pendidikan namun tidak sesuai dengan passion atau minat kerjanya. Pekerjaan adalah suatu rangkaian keterampilan dan kompetensi tertentu yang harus selalu ditingkatkan dari waktu ke waktu dengan mengharapkan atau tidak mengharapkan imbalan dan bertanggungjawab kepada orang lain (Wiltshire, 2016).

Penelitian Agustin, R.P., et al., (2019) menyatakan bahwa 69,1\% ibu mengalihkan perhatian anak-anak dengan gadget saat mereka bekerja. Penelitian American Association of Pediatrics (AAP) menunjukan hampir semua anak-anak (96,6\%) menggunakan gadget, dan alasan orangtua memberikannya adalah karena gadget membantu anak tetap tenang ketika ibu bekerja (70\%) (Kabali et al., 2015). Ibu yang bekerja membantu untuk menambah tingkat perekonomian keluarga untuk memenuhi segala kebutuhan yang diperlukan terutama dalam memberikan lingkungan yang aman, nyaman dan pemenuhan nutrisi anak untuk mengoptimalkan perkembangannya (Sujianti, 2018). Peneliti berasumsi tidak adanya hubungan pekerjaan dengan tingkat kematangan sosial anak prasekolah di Kelurahan $\mathrm{X}$ disebabkan oleh ibu yang bekerja bukanlah satu-satunya hal yang bisa menghambat perkembangan sosial anak. Jika ibu bekerja namun tetap memantau \& menstimulus perkembangan sosial anaknya di sela-sela rutinitas pekerjaannya dengan baik maka anak akan tetap berkembang dengan baik. Sebagian besar anak-anak lebih sering diasuh oleh pembantu atau oleh neneknya dan juga jarang diberikan stimulus. Anak lebih sering dibiarkan bermain dengan gadget-nya. Penelitian Agustin, R.P., et al., (2019) menyatakan bahwa berdasar hasil uji Spearman rho statistical, diperoleh nilai $=0,000 \quad(\rho<0,05)$ dengan yang berarti penggunaan gadget, berhubungan dengan perkembangan emosi anak prasekolah, sehingga perlu didampingi oleh orang tua. Bahkan sebaiknya dapat mengalihkan perhatian anak dengan mengenalkan permainan tradisional. Ini bisa menjadi cara bagi orang tua untuk merangsang dan mengembangkan keterampilan emosional anak-anak.

Jarak kelahiran yang pendek seringkali menyebabkan gangguan tumbuh 
kembang pada anak karena ibu terbagi fokus pada kehamilannya sehingga akan menyebabkan kurangnya stimulasi mental untuk kematangan sosial anak yang diberikan ibunya. Pengetahuan adalah hasil penginderaan manusia, atau hasil tahu seseorang terhadap suatu objek dari indra yang dimilikinya (Notoatmodjo, 2014). Peneliti berasumsi bahwa tidak adanya hubungan pengetahuan dengan tingkat kematangan sosial anak prasekolah terjadi dikarenakan meskipun orangtua memiliki pengetahuan yang baik namun kurang memberikan perhatian atau dukungan berupa stimulus untuk anak mengembangkan potensi yang mendukung peningkatan kematangan sosial maka kematangan sosial anak tidak akan bertambah karena perhatian dari orang sekitar mempengaruhi pertumbuhan dan perkembangan anak (Hayati. N, 2010). Hal ini didukung oleh hasil penelitian Mahanani, M (2015) bahwa hasil uji korelasi didapatkan $p$ value $=0,000(p<0,05)$ yang berarti ada hubungan signifikan antara perhatian orangtua dengan perkembangan kematangan sosial anak. Pada penelitian ini, hasil kuesioner menunjukan ibu dengan pengetahuan baik sebanyak 89.2\%. Didapatkan hasil bahwa sebagian besar ibu sudah mengetahui manfaat, dampak penggunaan, dan fitur-fitur di dalam gadget. Hasil kuesioner menunjukan sebagian besar ibu mengawasi penggunaan gadget , membatasi dan memilihkan program yang baik untuk diakses oleh anak. Penelitian Imron, R., 2017 menyatakan ada hubungan antara lama dan frekuensi penggunaan gadget dengan tingkat kematangan sosial anak prasekolah ( $\mathrm{p}$ value $=0,001$ ). Durasi yang cukup lama akan mempengaruhi perkembangan pribadi anak mengarah kepada individualisme karena tidak berinteraksi atau berkomunikasi dengan lingkungan atau teman sebayanya dengan waktu yang lama (Simamora, 2016). The American Academy of Pediatrics (2016) mengharapkan para orang tua memberikan batasan waktu pada penggunaan gadget untuk anak-anak. Peneliti berasumsi bahwa adanya hubungan lama bermain gadget dengan tingkat kematangan sosial anak prasekolah dikarenakan walaupun tingkat bermain anak rendah, namun anak terus menerus terpapar gadget dan membuatnya tidak berinteraksi dengan lingkungannya, ini membuat anak mengarah kepada individualisme.

\section{KESIMPULAN DAN SARAN}

Tidak adanya hubungan karakteristik ibu (usia, pendidikan, pekerjaan dan paritas) dan pengetahuan ibu dengan tingkat kematangan sosial anak prasekolah dan adanya hubungan lama bermain gadget tingkat kematangan sosial anak prasekolah. Pentingnya keterlibatan orangtua dalam pendampingan dan pembatasan waktu untuk anak bermain gadget, agar tetap dapat melakukan interaksi social dengan keadaan sekitarnya.

\section{UCAPAN TERIMA KASIH}

Peneliti mengucapkan terimkasih kepada kelurahan Cigadung Pandeglang yang telah membantu dalam proses pengambilan data. Terimakasih juga kepada STIK Sint Carolus dan pihak-pihat yang berperan dalam mensuport kami sehingga penelitian ini dapat diselesaikan.

\section{DAFTAR PUSTAKA}

Agustin,R.P., Saidah, Q.I., Anggoro,S.D., Huda,N., Widayanti,D.M., Priyantini,D.,\& Nurlela, L. (2019). The Relationship Between The Use Of Gadget And Emotional Development Of Preschool Children. The Malaysian Journal of Nursing, 11(2), 97-102.

Al-Yaouby, M. (2017). Dampak Penggunaan Gadget Pada Anak Usia Prasekolah. 265.

American Academy of Pediatrics. (2016). American Academy of Pediatrics Announces New Recommendations for Children's Media Use. Availabe from: https//www.aap.org/enus/about-the-aap-press-

room/Pages/American-Academy-ofPediatrics-Announces-New-

Recommendations-for-ChildrensMedia-Use.aspx

Arifin, S. (2015). Hubungan Tingkat Pendidikan dan pola asuh ibu dengan perkembangan motorik halus anak. repository.ump, 1-27.

Chusna, P. A. (2017). Pengaruh Media Gadget Pada Perkembangan Karakter Anak. Dinamika Penelitian, 17, 2.

Fajriana. (2015). Tingkat Kecanduan Gadget di usia dini semakin mengkhawatirkan. Retrieved Agustus 1, 2019, from CNN Indonesia: http://www.cnnindonesia. com/teknologi/20151103093518- 
185-89078/tingkat-kecanduan-gadget-diusia-dini-semakinmengkhawatirkan/

Fitria, N. (2016). Karakteristik Orang Tua dan Perkembangan Balita. Jurnal Care Vol.4, 1-12.

Hardjawikarta, C. G. (2018). Perancangan media interaktif yang dapat menstimulasi perkembangan kreativitas anak usia dini (Golden age, 2-5 tahun). Media Peneliti, 1-9.

Hayati, N. (2010). Peran Orang Tua dalam Pendidikan Anak Usia Dini. FIP UNY.

Hudaya, A. (2018, April). Pengaruh Gadget Terhadap Sikap Disiplin Dan Minat Belajar Peserta Didik. Research and Development Journal Of Education, 4, 1-12.

Imron, R. (2017). Hubungan penggunaan gadget dengan perkembangan sosial dan emosional anak prasekolah di Kabupaten Lampung Selatan. Jurnal Keperawatan, 148-154.

Jati, H. (n.d.). Segmentasi Mahasiswa Program Studi Ilmu Komunikasi UAJY dalam menggunakan gadget. Retrieved Juli 29, 2019, from http:ejournal.UAJY.ac.id

Kabali, H.K., Irigoyen, M.M., Nunez-Davis, R., Budacki, J.G., Mohanty, S.H., Leister, K.P. \& Bonner, R.L. (2015). Exposure And Use Of Mobile Media Devices By Young Children. Pediatrics, 136(6), pp 1044-1050.

Mahanani, M. (2015). Hubungan Perhatian orangtua dengan perkembangan sosial anak usia 4-5 tahun di desa birit kecamatan wedi kabupaten klaten. eprints UNY, 1-105.

Meiri, E., Suprayitno, E., Damayanti, C. N., \& Fatoni, A. F. Hubungan Penggunaan Gadget Dengan Tingkat Perkembangan Kognitif (Tingkat Prestasi) Pada Anak Usia 7-11 Tahun Di SDN Kebun Dadap Timur Kabupaten Sumenep.

Notoatmodjo. (2014). Metodologi Penelitian Kesehatan. Jakarta: PT.Rineka Cipta.

Rini, A. K. (2016). hubungan pendidikan ibu dan paritas dengan perkembangan anak di PAUD Baitul Izzah. Jurnal STIKes Tri Mandiri, 1-6.

Setianingsih, S. (2018). Dampak penggunaan gadget pada anak usia prasekolah dapat mengingkatkan resiko gangguan pemusatan perhatian dan hiperaktivitas. Gaster Jurnal Kesehatan, 16.
Simamora. (2016). Persepsi Orangtua Terhadap Dampak Penggunaan Gadget Pada Anak Usia Pendidikan Dasar 